ELECTROANALYTICAC CHEMISTRY AND INTERFACLAL ELECTROCHEMISTRY

Elsevier Publishing Company, Amsterdam - Printed in The Netherlands

\title{
THE POLAROGRAPHY OF AQUEOUS PERTECHNETATE ION
}

CHARLES L. RULFS, RICHARD PACER AND ALFRED ANDERSON

Department of Chemistry. University of M2chigan, Amn Arbor, Michigan (U.S.A.)

(Received Novernber Ioth, 1966)

The electrochemical and polarographic behavior of aqueous pertechnetate media is rather complex1-3, yet it is probably not as anomalous as has been suggested4.5. Macro-electrolysis from non-complexing acidic media leads to partial electrodeposition of technetium metal with some separation of technetium dioxide ${ }^{6,7}$. The polarographic and coulometric behavior of pertechnetate in sulfuric acid is compatible with this, and hydrochloric acid is only slightly more "complexing"' in character1,8. In complexing or non-complexing, acidic to neutral media, the expected three- or four-electron first stage of pertechnetate reduction occurs at relatively positive potentials and this fact has been established coulometrically1,2.8-10. The rapidity of the chemical reduction of acidic pertechnetate in contact with mercury has been noted 1.8.10, but does not appear to have been recognized in many of the polarographic papers $3,4,14$.

Coltow et al. ${ }^{4}$ have calculated apparent polarographic $n$-values for pertechnetate reductions in $\mathrm{KCl}$, perchloric acid and other media, which include the following approximations (with generalizations on their validity):

(a) Use of the classical Ilkovic equation (leads to ca. 10\% error in $n)^{3}$.

(b) Use of infinite-dilution $D^{\circ}$-values (actual $D$ may be $\pm 20 \%$ different).

(c) Use of an obsolete value of $D^{0}$ for $\mathrm{ReO}_{4}-, 1.37 \times \mathrm{IO}^{-5} \mathrm{~cm}^{2} \mathrm{sec}^{-1}$, used for $\mathrm{TcO}_{4}-$ by analogy ( $\mathrm{I} .46$ preferable since 1948 , but $\mathrm{I} .48$ has now been measured for $\left.\mathrm{TcO}_{4}^{-}\right)^{11.12}$.

(d) Use of a "constant" value of $\left(m^{\prime} t^{\prime}\right)$ for waves at potentials of $E_{t}-0.5$ to $-\mathrm{I} .8 \mathrm{~V}$ (typically, there is about $7 \%$ variation over this range).

The conclusions based on this early work have been restated ${ }^{5}$ with little attention to subsequent coulometric evidence. Another author ${ }^{13}$ notes the disagreement in the literature and cites the conflicting results. This degree of confusion appears to be unwarranted, since several sets of authors 1.3.8.9 have explored and defined the conditions for useful polarographic and coulometric measurements of technetium. The claim4.5 that, while perrhenate in $4 M$ perchloric acid is reduced by three electrons at $-0.4 \mathrm{~V}$ (and pertechnetate should undergo a similar reduction at more positive potential) pertechnetate showed no reduction prior to the supporting electrolyte discharge (about - I.0 V), is surprising. Claimed reductions ${ }^{4.5}$ of (VII $\rightarrow$ VI) and (VI $\rightarrow \mathrm{IV}$ ) in $4 \mathrm{M} \mathrm{HCl}$ at -0.52 and $-0.68 \mathrm{~V}$, appear to be incompatible with coulometric evidence ${ }^{1,8}$ for a four-electron reduction at ruuch more positive potentials.

Pertechnetate reductions in hydrochloric and in sulfuric acids have been studied and reported in some detail1,8. A re-examination of the system in perchloric 
acid media seemed to be desirable. The nature of technetium "amalgam" has also been examined briefly.

EXPERIMENTAI

A conventional dropping mercury electrode assembly was used with a manual polarograph, the Fisher Elecdropode. All potentials measured are relative to the saturated calomel electrode, using agar-salt bridges to lessen the contamination of test solutions by $\mathrm{Cl}^{-}$. A hydrogen-oxygen gas coulometer was used with a large mercury pool coulometric cell. The efflient from purging acidic solutions with purified $\mathrm{N}_{2}$, contains a little $\mathrm{HTcO}_{3}$ which is trapped in alkali. Details of the equipment and of the requisite precautions for coulometry have already been given $2,8,10$.

Ammonium pertechnetate solutions of good purity were obtained from Oak Ridge National Laboratory. Concentrations were checked by ultraviolet spectrophotometry at the $246 \mathrm{~m} \mu$ doublet and at $287.5 \mathrm{~m} \mu(\varepsilon=6,160$ and 2,316$)$.

A small decade scaler and thin-wall Geiger tube sufficed for the simple relativecounting of ${ }^{99} \mathrm{Tc}$.

A size 2 International Centrifuge was used. The accessories and the loading employed, gave an estimated angular velocity of $3 \mathrm{I} 4 \mathrm{rad} / \mathrm{sec}$ and an effective arm length of $23 \mathrm{~cm}$.

The dropping technetium "amalgam" electrode was freshly prepared in situ. Acidic aqueous pertechnetate was electrolysed, at $5-6 \mathrm{~V}$ with stiring, into a pool of mercury in the reservoir. After 30-40 $\mathrm{min}$ and without removal of the aqueous layer or breaking of the current, about $25 \mathrm{ml}$ of mercury was discarded from a side tube located just above the D.M.E. capillary. This brought fresh amalgam immediately down to the active electrode region for the polarographic testing. The arrangement was tested with cadmium amalgam and behaved as expected. The amalgam flow eventually slows and tends to plug the capillary, but not before meaningful tests can be run.

RESULTS AND DISCUSSION

The average $n$-value of 8.54 obtained by ColTow et al. ${ }^{4}$ for pertechnetate reduction in $2 \mathrm{M} \mathrm{KCl}$ is close to 7 (6.8), if the latest value of $D_{\mathrm{TcO}_{4}^{-}}^{\mathbf{0}}$ is used. Probably no great importance should be placed on this fact in view of the remaining uncertainties in such a calculation, and of the discordant results reported by AsTHEIREER AND SCHWOCH $\mathrm{U}^{-3}$ for similar media. In neutral $\mathrm{LiCl}$ for example, these authors claim an earlier step for the (VII $\rightarrow$ V) reduction and the $n=7$ level does not lie on a plateau.

It appears to be well established by coulometry ${ }^{1,9}$ that a four-electron reduction of acidic pertechnetate occurs at positive potentials, although in $4 M \mathrm{HCl}$ the potential only represents that which is perrwitted by the anodic calomel discharge at the D.M.E. A subsequent reduction to metal is found at $-0.9 \mathrm{~V}$. The contrary report 4.5 of ill-defined (VII) $\rightarrow$ (VI) and (VI) $\rightarrow$ (IV) waves at -0.5 and -0.7 apparently results from two factors:

(I) Prio:r chemical reduction of most of the (VII) by mercury to form intermediate-state species.

J. Electroanal. Cikem.. Is (1967) 61-66 
(2) Failure to examine the region of positive potential for remaining (VII).

The use of $0.25 M \mathrm{~K}_{2} \mathrm{SO}_{4}$ or $0.5 \mathrm{M} \mathrm{KCl}$ with $0.1 M \mathrm{KOH}$, gave a (VII) $\rightarrow$ (IV) wave at $-0.8 \mathrm{~V}$ and a (IV) $\rightarrow$ (III) step at - I.o V. This interpretation ${ }^{1,8}$ of the steps is supported by coulometric work and should probably, but not necessarily, replace the alternative interpretation ${ }^{4.5}$ (based on $D$ and the Ilkovič) given for o.I $\boldsymbol{M}$ $\mathrm{KOH}$ alone. The latter reports (VII) $\rightarrow$ (V) and (V) $\rightarrow$ (IV) processes at -0.85 and -I.I5 V, respectively. The first group did not find the second wave to be pure diffusion-limited which would invalidate the calculation of $n$ via the Ilkovič equation.

Pertechnetate solution (0.5-0.I $\mathrm{m} M$ ) in a series of $4-0.01 M$ (the latter, with ca. o.I $M \mathrm{NaClO}_{4}$ ) perchloric acid media were de-aerated in the absence of mercury. Polarography at the dropping mercury electrode was then conducted as expeditiously as possible. After a polarographic run, the solution and accumulated mercury were shaken intermittently for $5 \mathrm{~min}$ in a weighing bottle, returned to the cell and deaerated together for 5 min more, and then re-examined polarographically.

Two successive stages of reduction are observed. The position of Wave I shifts from an apparent $E_{t}$ of $c a$. $+0.05 \mathrm{~V}$ to $-0.17 \mathrm{~V}$, as a function of $\mathrm{pH}$. Its slope indicates irreversibility, and its magnitude (in the absence of significant pre-reduction by mercury) is greater than that of the less reproducible, second wave. The smaller, more negative Wave II is found at -0.58 to $-0.73 \mathrm{~V}$. Its position seems to drift to more negative values with increase in $\mathrm{pH}$. This wave is less well-defined, however, tending to merge with the subsequent discharge of hydrogen ion. Moreover, we suspect that its position is partly defined by the extent to which $a$ priori intermediate technetium-states have been formed from chemical reduction with the mercury. Its slope is irreversible for a more than one-electron process.

With solutions more concentrated than $\mathrm{O}$.I $M$ in $\mathrm{HClO}_{4}$, contact with mercury before polarography can result in an extensive decrease in Wave I. With $4 M \mathrm{HClO}_{4}$,

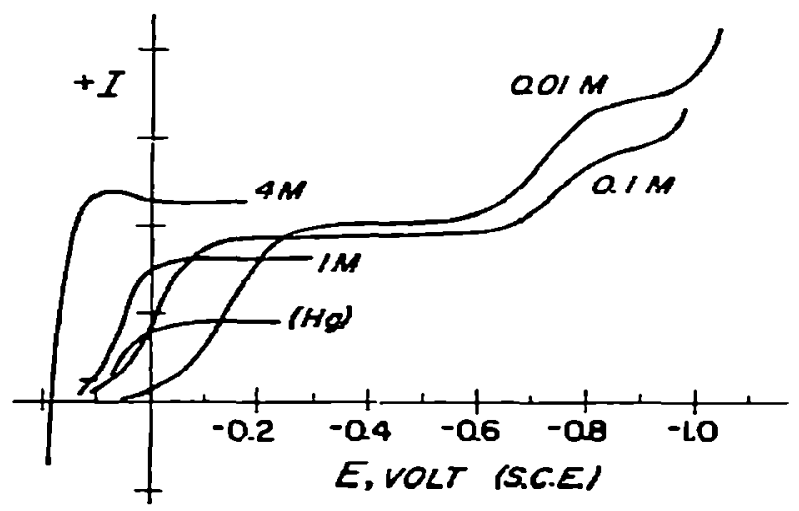

Fig. I. Polarographic behavior of pertechnetate ion in various concns. of $\mathrm{HClO}_{4}$ (o.or $M$ includes o. ro $M \mathrm{NaClO}_{4}$ ). The effect of pre-contact with $\mathrm{Hg}$ is shown for the I $M I$ medium.

however, the solubility of the mercury salts resulting from this prereduction yields an extensive cathodic current, extending from the most positive potential permitted by the anodic mercury discharge. The general appearance of the waves is shown in Fig. I.

Coulometry in $0.5 \mathrm{M} \mathrm{HClO}_{4}$ with 0.3 mmoles of $\mathrm{TcO}_{4}^{-}$present at $-0.2 \mathrm{~V}$ 
S.C.E. gives $x$-values of $3.92,3.95$ for Wave $I$. No doubt, in driving a coulometric run at a large mercury pool, the gross faradaic result involves a mixed process. However, the total requirement for the combination of processes,

and,

$$
\mathrm{Tc}(\mathrm{VII})+4 e^{-} \rightarrow \mathrm{Tc}(\mathrm{III})
$$

$$
\mathrm{Tc}(\mathrm{VII}\}+\mathrm{Hg}(\mathrm{O}) \rightarrow \mathrm{Tc}(\mathrm{III})+\mathrm{Hg}(\mathrm{I})
$$

followed by,

$$
\mathrm{Hg}(\mathrm{I}) \rightarrow \mathrm{Hg}(\mathrm{O})
$$

is probably correct for Wave I. Moreover, the final black precipitate that forms seems to be $\mathrm{TcO}_{2}$, not $\mathrm{Tc}_{2} \mathrm{O}_{3}$, the product being partially reoxidized by hydrogen ion, as was true in sulphuric acidio. In hydrochloric acid or in phosphate media, moderately stable green solutions of Tc(III) complexes are obtained 1.2,8.9.

The shift in $E_{i}$ of Wave I with $\mathrm{pH}$, conforms with the equation,

$$
E_{t}=0.06-0.106 \mathrm{pH} \text {. }
$$

If the four-electron status of the wave is accepted, this agrees closely with an eighthpower dependence on the activity of hydrogen ion. This implies complete stripping of the four pertechnetate oxygens in the primary electrochemical reduction process,

$$
\mathrm{TcO}_{4}-+8 \mathrm{H}^{+}+4 e^{-\rightarrow} \rightarrow \mathrm{Tc}^{3+}+4 \mathrm{H}_{2} \mathrm{O}
$$

This is also trie in other media', although the irreversibility of the wave (slope, criterion) does not allow positive assertions on this point.

The occurrence of technetium electrodeposition on to or into a mercury cathode is evident from polarographic studies, but the status of the product is not clear.

Technetium metal powder digested with mercury at $300^{\circ}$ gives no evidence of dissolution. Since the metal powder undoubtedly carries some oxide film and because the melting point of technetium is $2,150^{\circ}$, this result is not surprising. Acidic solutions of periechnetate are slowly reduced, ultimately to the metallic state, by simple contact with a pcol of mercury. Some of the technetium is contained within the mercury, but an exterior film is also evident. An $0.006 \mathrm{M}$ solution of $\mathrm{TcO}_{4}-$ in I $\mathrm{M} \mathrm{H}_{2} \mathrm{SO}_{4}$ was electrolysed at nearly ro $\mathrm{V}$, applied, into a mercury cathode. An interior portion of the mercury was thieve-sampled, dissolved in nitric acid and counted. Molalities of technetium in mercury up to 0.005 are not difficult to obtain in this manner. The question remains of whether this product is a true amalgam or merely a finely divided suspension of technetium.

Centrifugation provides a simple experimental approach and gives results which can be interpreted within predictable limitations. A measurable centrifugal separation of particulate technetium $(d=I I .5 \mathrm{~g} / \mathrm{ml})$ in liquid mercury wonld require that the particle size of the technetium exceed a certain value. With the assumptions of Stoke's Law applied to a centrifugal force, the sedimentation equation was solved for the available equipment. With our equipment, we estimate an angular velocity of $314 \mathrm{rad} . / \mathrm{sec}$ and an effective arm length of $23 \mathrm{~cm}$. Only Io min would be needed to displace (upward, of course) a technetium particle of I,000 A diameter through $x$ cm of mercury, and 16.7 h for a roo-A particle; but $7^{\circ}$ days would be required to displace a ro- $A$ particle this same distance. The measurements would not be sensitive 
for particulate sizes below about $20 \mathrm{~A}$, and negative results would not distinguish a homogeneous solution from such fine particles.

After an electrolysis, a sample withdrawn from within the mercury pool cathode was subjected to $3 \mathrm{~h}$ of centrifuging. Small portions were removed from the top and bottom of the centrifuge tube (about $4 \mathrm{~cm}$ apart), dissolved in nitric acid, neutralized with ammonia, and counted. In an earlier run, results comparable with those reported were obtained, but the background constituted a larger portion of the total activity. The following data were obtained, after correction for a blank, for three samples from a second run:

\begin{tabular}{llc}
\hline Top of tube & Bottom of tube & Ratio \\
\hline 231 counts/10 min, g Hg & 40 counts/10 min, g Hg & 5.8 \\
248 & 80 & 3.1 \\
215 & 55 & Av. $\frac{3.9}{4 \cdot 3}$ \\
\hline
\end{tabular}

From the approximately four-fold concentration of technetium under these conditions, one may estimate the particle size of the dispersed technetium metal as lying within the range $10^{-6}-\mathrm{IO}^{-5} \mathrm{~cm}$. This technique does not elininate the possible existence of a mercury-insoluble $\mathrm{Tc}-\mathrm{Hg}$ compound, and refers to the status of the mixture approximately $4 \mathrm{~h}$ after formation.

Provision was made for the preparation of a technetium-in-mercury deposit in the upper mercury reservoir of a conventional D.M.E. assembly. Without the dangers of re-solution or air-contact, freshly made "amalgam" could then be brought immediately down to the D.M.E. by simply removing the "dead-space" volume of mercury (contained in the stand-tube) via a side cock mounted above the capillary. In three such experiments it was confirmed (radiochemically) that technetium was actually present within the mercury exiting from the capillary. The system was operated into freshly de-aerated o.I $M \mathrm{HCl}$ and polarographically scanned for the existence of anodic waves. The available potential region amounted to approximately $+0.05 \mathrm{~V}$ (where anodic calomel discharge occurs) to $-0.85 \mathrm{~V}$ S.C.E. where the toe of the cathodic hydrogen wave begins (this is more positive for technetium in mercury than with pure mercury).

Only the usual shape of residual current curve, with currents of less than o.I $\mu \mathrm{A}$, was observed in these experiments. There was no evidence of anodic dissolution of technetium. When solutions were examined after more than $30 \mathrm{~min}$, during which time the dropping continued and nitrogen was loosely maintained as a blanket but not recirculated through the solution, less than $0.5 \mu \mathrm{A}$ of cathodic wave sometimes developed. This wave appeared at potentials more negative than $-0.6 \mathrm{~V}$, corresponding to the presence of small amounts of $\mathrm{Tc}$ (III), or lower states. Evidently, $\mathrm{H}_{3} \mathrm{O}^{+}$ and traces of $\mathrm{O}_{2}$ permit some dissolution.

Neither experiment alone, nor the two in conjunction, completely characterizes the nature of technetium electrodeposited into mercury. The negative results of the anodic dissolution, however, are compatible with the sizeable particles deduced from centrifugation. 


\section{ACKNOWLEDGEßENTS}

Support by the U.S. Atomic Energy Commission, Contract AT(II-I)-I483, is gratefully acknowledged.

\section{SUMMARY}

The polarographic reduction of pertechnetate in $4-0.01 M$ perchloric acid media takes place in two stages. The $E_{\ddagger}$ of the more positive wave at to.Io to - 0.I7 V S.C.E. is pH-dependent, $E_{t}=0.06-0.10_{6} \mathrm{pH}$. Coulometry indicates a fourelectron process, $\mathrm{TcO}_{4}+8 \mathrm{H}^{+}+{ }_{4} e^{-}=\mathrm{Tc}^{3+}$. A second wave at $-0.73 \mathrm{~V}$ appears to involve the three-electron step (III) $\rightarrow(\mathrm{O})$.

Technetium electrodeposits into mercury in a finely-divided form. Centrifugation of the product indicates particles of $10^{-5}-10^{-6} \mathrm{~cm}$ diameter. A freshly-prepared technetium "amalgam" dropping-electrode showed no anodic polarographic activity in $0.1 \mathrm{M} \mathrm{HCl}$ from -0.8 to + $0.05 \mathrm{~V} \mathrm{S.C.E.,} \mathrm{indicating} \mathrm{little} \mathrm{solubility,} \mathrm{or} \mathrm{true} \mathrm{arnal-}$ gam character.

\section{REFERENCES}

I G. B. S. Silaria, C. L. Rulfs and P. J. Elvisg. J. Chem. Soc., (1963) 2479 .

2 H. H. Mitler, M. T. Kelley AND P. F. Thomsisos, Advances in Polarography, edited by I. S. Longmuir, Vol. 2. Pergamon Press, Landon, r96o, Pp. TI6-26.

3 L. Astheimer AND K. Schwochau, $J$. Electroanal. Chem., 8 (:964) 382-89.

4 R. Coliox, J. Dalziel, W. P. Gruffith and G. Wilkinson, J. Chem. Soc., (1960) 71.

$j$ R. Coltos. The Chemistry of Rherizum and Technetium. John Wiley. London. New York, Sydney, 1965. Pp. I50-57.

6 J. D. EAkivs Axid D. G. Huarphries, J. Inorg. G Nucl. Chem., 25 (1963) 737.

7 R. E. Voltz and M. L. Holt, $J$. Electrochem. Soe., I 4 (1967) 128.

3 G. B. S. Salaria, C. L. Rulfs and P. J. Elving, Anal. Chem., 35 (1963) 979.

9 A. A. TERRY AND H. E. ZiITEL, Anal. Chem., 35 (I963) 614.

Io C. L. RULFs, R. PACER AND R. Hirsch, J. Inorg. E Nucl. Chem., 29 (1967) 681.

II C. L. Rulfs and P. J. Elving. J. Am. Chem. Soc., 73 (195I) 3284.

12 K. SCHWOCHAU AND L. AStheimeR, Z. Nalurforsch., I ja (1962) 820.

I3 R. D. PEAcock, The Chemistry of Technetium and Rnenizm. Elsevier. Amsterdam, London, New York: 1966, p. 35 .

I4 R. J. MAGEE, I. A. P. SCOtt AND C. L. WILSON, Talanta, 2 (1959) 376.

$J$. Electroanal. Chem., $15(1967) 61-66$ 